\title{
The Use of Auditory Feedback in Call Centre CHHI
}

\author{
Anette Steel, \\ Matt Jones, Mark Apperley \\ Department of Computer Science \\ University of Waikato \\ Hamilton, New Zealand \\ \{acs9, mattj, m.apperley\}@cs.waikato.ac.nz
}

\begin{abstract}
Initial investigations have been carried out to evaluate issues of the computer-human-human interaction (CHHI) commonly found in call centre scenarios. These investigations suggest some benefits in the use of auditory icons and earcons.
\end{abstract}

\section{Keywords}

Call centre interaction, CHHI, CHI, auditory feedback, visually impaired software

\section{INTRODUCTION}

Providing good customer service is crucial to many organizations. It is increasingly common that a large part of customer service is provided through call centres. There are several interactions that take place during the telephone call to a call centre, shown in Figure 1. The customer is the person who is interested in the product or service, but she is not directly interacting with the computer system. The agent is interacting both with the computer and with the customer. As the interaction is carried out over the phone, the customer is not able to see the computer. Indeed, the customer might not even be aware that a computer system is involved. We call these sorts of collaboration Computer-Human-HumanInteraction (CHHI).

In this paper we propose the use of non-verbal auditory feedback to improve CHHI. We motivate our novel scheme by a series of observational studies at major callcentres. We have carried out an initial user-based study to examine the effectiveness of the approach.

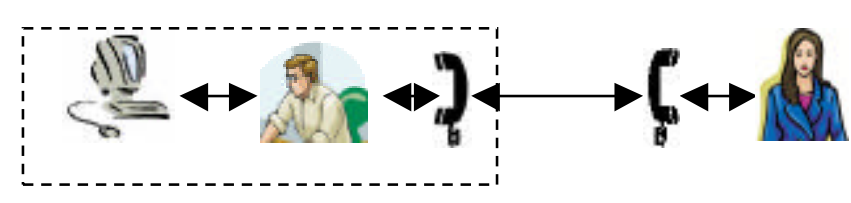

Figure 1. Computer-Human-Human Interaction: computer operated by agent communicating with customer.

\section{PROBLEMS AND ISSUES}

Despite the growing importance of call centres, very little has been published that is directly relevant to the kind of collaborations that take place.
However, Bowers and Martin [1] identified a number of issues that are important: pace of interaction and system responsiveness; information format; display of engagements; the design of closing dialogue; and system documentation. Of these, display of engagement (that is, showing the activity taking place between the agent and computer), is of particular interest to our work.

\section{Call centre observations}

In order to gain some initial insights into CHHI, we visited three major New Zealand call centres and listened in on 150 telephone calls involving 12 agents. We made notes of interesting communications and computer system use. After each call, the agent was also interviewed.

For agents, many conventional HCI issues, such as interface learnability and feedback, also apply to CHHI. However, there are issues specific to CHHI. For example, learnability is particularly important as many call centres have a very high staff turnover; and, system feedback sometimes needs to be communicated to the agent and customer.

During the observations, we paid particular attention to situations were the agent verbalised their activity with the system to the customer. Agents often communicated system state, telling the customer, for example, that transactions had been completed. We also noted that many of the agents pressed down hard on the computer keys when typing. They did this to let the customer know they were engaged in an activity and should not be interrupted.

\section{IMPROVING CHHI}

Customers in CHHI cannot see the computer screen and therefore could be considered visually impaired with regard to the computer interface.

Much work (e.g., [3]) has been done to develop effective interfaces for the visually impaired. This literature can be revisited to aid research into CHHI. In call centre interaction, the customer does not need to know all the information at the computer interface but, as our observational studies indicated, there are still many times when the agent conveys interface information to the customer.

Two types of auditory feedback - auditory icons and earcons - have been found to be effective in improving interactions for visually impaired and other users.

Auditory icons are realistic, everyday sounds (e.g. paper shuffling) that represent concrete system objects or events (e.g. dragging a file across the desktop) [4]. 
Earcons, in contrast, are abstract syntactic tones [2]. They are composed of sounds that vary in rhythm, pitch, timbre, register and dynamics. Earcons can be combined to produce more complex auditory messages.

Using information from the observational studies, we designed auditory icons and earcons for objects and events for our trial call centre system. The auditory icons were: agent types - a distinct keying sound is heard; system is busy - ticking clock noise is played; agent flicks between information screens - paper shuffling noise played. Two earcons were used to represent the amount of information on the screen - a rising, fast, high pitched sequence for complex screens; a slow, low pitched one where the amount of information (and the demands on the agent) are low.

\section{PRELIMINARY STUDY}

We have carried out an initial study into the impact of auditory feedback on CHHI. The hypotheses were that the addition of auditory feedback would lead to: i) improved flow of conversation and progress of calls; and, ii) improved customer satisfaction.

We designed a simulation based on a real call centre. Two versions of the system were used, one without and the other with auditory icons and earcons.

22 participants (10 males and 12 females) with ages varying from 18-74 years took part in the study. It was a between subject study, that is, half the participants interacted with the system that had auditory feedback and the others with the conventional, no auditory feedback system. The participants were asked to telephone the call centre and perform two tasks: change their address and enquire why a bill was higher than expected. All sessions involved the same customer service agent and were videotaped.

To test the hypothesis that call progress and flow is affected by auditory feedback we gathered a range of quantitative data. For each call, we recorded the time to complete tasks. After all subjects had completed the tasks, we analysed the video recordings and counted the occurrences of three event types during each call: (1) when the agent gave feedback; (2) when the subject asked for feedback; and, (3) when the subject provided information to the agent at an inappropriate time (i.e. when the agent needed to focus their attention on the computer system)

To explore the impact of feedback on customer satisfaction we asked each subject to complete a questionnaire at the end of his or her session. This questionnaire included a Likert scale rating of satisfaction and an open comment section.

\section{Results}

\section{Call progress and flow}

The average time to complete a call for the system with auditory feedback (367s) was lower than for the system with no feedback (398s). In an industry where milliseconds matter, 31 seconds multiplied over thousands of calls a day would have a dramatic impact. The result, though, is not statistically significant; a larger study is needed to test the impact on timing further.
Table 1. shows the event data relating to call progress and flow. The statistically significant $(t$-test, $\mathrm{p}=0.01)$ improvement was a reduction in the number of times a subject attempted to provide information to an agent at an inappropriate time (event type 3).

\begin{tabular}{|l|l|l|l|l|l|l|}
\hline Condition & $\begin{array}{l}\text { Mean } \\
\# 1\end{array}$ & $\begin{array}{l}\text { Dev. } \\
\# 1\end{array}$ & $\begin{array}{l}\text { Mean } \\
\# 2\end{array}$ & $\begin{array}{l}\text { Dev. } \\
\# 2\end{array}$ & $\begin{array}{l}\text { Mean } \\
\# 3\end{array}$ & $\begin{array}{l}\text { Dev. } \\
\# 3\end{array}$ \\
\hline $\begin{array}{l}\text { No } \\
\text { feedback }\end{array}$ & 7.18 & 2.3 & 0.45 & 0.8 & 2 & 1 \\
\hline $\begin{array}{l}\text { Auditory } \\
\text { feedback }\end{array}$ & 6.45 & 2.4 & 0.54 & 0.7 & 0.81 & 1.1 \\
\hline
\end{tabular}

Table 1: mean number of times (with standard deviations) event types 1 (agent gives feedback), 2 (subject asks for feedback) and 3 (subjects gives information at inappropriate time) occurred during a call.

\section{Subject satisfaction with call}

The average rating of satisfaction was very slightly better for the no feedback condition (5.58) than the auditory feedback one (5.72). This was not statistically significant (Wilcox sum rank). However, although only $18 \%$ of subjects who used the auditory feedback system commented that sounds could be distracting, many $(60 \%)$ stated the feedback was helpful.

\section{CONCLUSION AND ONGOING WORK}

Call centres are significant users of interactive technologies. This work helps in the understanding of the new types of computer-human-human-interaction involved in these situations.

We have presented an initial argument for adapting and applying previous research on visual impairment and in particular auditory icons and earcons. Our work suggests such feedback can reduce inappropriate interruptions from customers. Although overall the results indicate only limited benefits, we feel a larger study involving more sophisticated and targeted icons and earcons is merited. Table 1. shows that our agent provided much verbal feedback in both cases. An interesting further study would to instruct the agent not to give feedback where auditory icons and earcons were available.

\section{REFERENCES}

1. Bowers J. \& Martin D. (2000). Machinery In The New Factories: Interaction And Technology In A Banks Telephone Call Centre. Proc. On The ACM 2000 Conference On Computer Supported Cooperative Work, December 2-6, 2000, Philadelphia, PA USA.

2. Brewster S.A. (1997). Using Non-Speech Sound to Overcome Information Overload. Special Issue On Multimedia Displays, 17, 179-189.

3. Edwards A. (1988). The Design Of Auditory Interfaces For Visually Disabled Users. Conference Proc. On Human Factors In Computing Systems. May 15-19, 1988, Washington United States. 83-88.

4. Mynatt E.D. (1994) Designing with Auditory Icons: How Well Do We Identify Auditory Cues? Proc. Of The Chi '94 Conference Companion On Human Factors In Computing Systems. April 24 - 28, 1994, Boston United States. 269-270 